К.К. Ельцова

\title{
ПСИХОЛОГИЯ «ЭЛИТАРНОСТИ»: СПОСОБЫ ПОСТРОЕНИЯ МЕДИЙНЫХ БРЕНДОВ В РУНЕТЕ
}

\begin{abstract}
Аннотация. Статья посвящена анализу дискурса элитарности, который используется рядом российских Интернет-проектов как инструмент создания собственных репутаций в качестве СМИ, предназначенных для наиболее образованных и квалифицированных групп современного отечественного общества. Речь идет о таких медиа как Afisha.ru, Bg.ru, Lookatme, Openspace (2008-2012), Colta, Esquire, "Сноб», которые (вос)производят один из наиболее заметных элитистких дискурсов в сегодняшней России. Исследование проведено на материалах, опубликованных изданиями данной группы в период с 2008 г. по 2013 г. Методом анализа дискурса в качестве ведущего аналитического инструмента в исследовании выявляются и систематизируются конкретные стратегии и механизмы конструирования репутации изданий сегмента как медийных продуктов, маркирующих высокий социальный статус представителей целевых аудиторий. В результате анализа, во-первых, подтверждено исходное предположение о противопоставлении себя отобранными проектами тому, что видится ими как издания для массовой аудитории - «глянцу». Притом в качестве базовой характеристики, определяющей "неглянцевость" или даже "антиглянцевость» того или иного издания изучаемого списка полагается "длинный текст", имплицитно представляемый в логике анализируемого дискурса как "качественный текст». Одновременно, риторика особенного, “элитарного», статуса того или иного из исследуемых медиа-проектов нивелируется, когда речь заходит об экономических аспектах существования подобных проектов. Наконеи, видимо, в силу влияния финансово-маркетологической риторики образ целевой аудитории как «просвещенного меньшинства» (выявленный на предыдущих этапах исследования) в данном случае дополняется образом "среднеинтеллигентного человека».

Ключевые слова: психология элитарности, статус-символизирующие практики, элитистский дискурс, элита, элитарность, медиа-репрезентации, дискурс-анализ, построение репутации бренда, конструирование аудитории, медиа-формат.
\end{abstract}

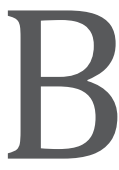

силу ряда политических и социокультурных обстоятельств, вопросы обозначения высокого социального статуса являются для российского общества, видимо, и по сей день предметом особого отношения и повышенной чувствительности.

Под обстоятельствами, сформировавшими подобное отношение, в узком смысле и прежде всего, в данной статье понимается развитие России в XX веке. После Октябрьской революции предшествующая смене политического строя социальная структура (предполагавшая, в частности, существование аристократии/дворянства и купечества как сословий) была упразднена, по крайней мере, в официальной риторике и идеологии всеобщего равенства, и в период советской власти возможности обозначения значимого социального статуса были ограничены. После распада СССР, сопровождавшегося, в том числе, трансформа- цией экономического уклада и представлений о стратификации социума, российское общество, по сути лишенное на протяжении нескольких предыдущих десятилетий самой мысли о допустимости и/или нормальности демонстрации социального неравенства (шире - отличия), принялось, в силу имеющихся представлений о престиже и успехе, “наверстывать упущенное".

Ввиду отсутствия в культуре подходящих для изменившихся после распада СССР социальных условий отработанных статус-символизирующих механизмов и практик, эти механизмы и практики в постсоветской России во многом изобретались заново. При этом ресурсами для подобного рода «изобретений» становились, во-первых, очередные заимствования и перенесение на отечественную почву статус-символизирующих практик современных западных обществ; во-вторых, попытки обращения к тем практикам обозначе- 


\section{Психология и психотехника 1(76) • 2015}

ния статуса, которые существовали в дореволюционной России.

И в том, и в другом случае ведущим механизмом формирования образцов престижного поведения и стиля жизни, соответствующих высокому статусу и маркирующих социальную успешность, и одновременно каналом транслирования подобного рода знаний широкой аудитории становились СМИ. Речь идет в первую очередь о классических глянцевых СМИ и телевидении (подразумеваются журналы и передачи, посвященные разнообразным аспектам образа жизни, в том числе, моде и модному поведению, повседневным практикам, вопросам построения карьеры, планирования досуга и отдыха, культуре еды и т.п.). Особенно велика роль подобных медиа в постсоветской России была в период с начала 1990-х до приблизительно середины-второй половины 2000-х гг.

Ближе к концу 2000-х гг. в силу ряда причин происходят изменения в запросе (части) общества на способы обозначения высокого социального статуса (и, предположительно, на представления об основаниях его обретения), и, соответственно, меняются и сами медиа об образе и стиле жизни, часто обозначаемые как «лайфстал-/lifestyle-CМИ». Основными причинами такого рода являются, с одной стороны, относительное экономическое благополучие середины 2000-х гг,, обеспеченное высокими ценами на нефть на мировом рынке, и доступность за счет института потребительского кредитования материальных статус-символов все большему количеству людей в стране, а соответственно, снижение значимости этих статус-символов; с другой - последовавший за “изобильными годами” финансовый кризис 2008 г. и обусловленная, в том числе, опасениями относительно ухудшения экономической обстановки в России и в мире, своего рода мода на "умное"/“интеллектуальное" и соответствующий ей пересмотр систем статуссимволов. В частности, в печатных глянцевых СМИ начинают публиковаться, получая значительное читательское внимание, материалы на политические и социальные темы (например, колонки Эдуарда Лимонова в GQ или интервью с сидящим в тюрьме Ходорковским в Esquire). Одновременно активно развиваются Интернет-издания, которые освещают широчайший спектр тем и вопросов образа жизни и городской повседневности. Более того, с распространением технологии Web 2.0 в создании подобных Интернет-изданий активное участие могут принимать и читатели-пользова- тели этих медиа (как скажем, в случае порталов Lookatme или Snob.ru), что часто меняет тот или иной проект, делая его “ближе” к запросам и интересам аудиторий.

Особый интерес, на наш взгляд, в этой связи представляет медиа-сегмент, оформившийся в России к концу 2000-х гг., который изначально - примерно в период 2005-2008 гг. - часто обозначался представителями входящих в него изданий как «интеллектуальный глянец». Речь идет о следующих проектах (как бумажных, так и Интернет-версиях): «Афиша» и ее тематические приложения, «Большой Город», Esquire, Lookatme и его тематические приложения, Openspace (2008-2012 гг.), «Сноб», W-O-S.ru, Colta.ru. Как уже отмечалось в наших предыдущих публикациях $[1 ; 2]$, издания позиционируют себя и воспринимаются (и своими аудиториями, и другими сообществами современного отечественного социума) как медиа, обращенные к наиболее образованным и прогрессивно мыслящим, “продвинутым”, представителям российского общества.

Отвечая на обозначившийся к середине-концу 2000-х гг. общественный запрос, именно такого рода издания предприняли эксперимент по совмещению «глянцевого», как чего-то легкого и приятного для восприятия, и «интеллектуального», как чего-то подразумевающего глубину, серьезность и соответствующий образовательный и интеллектуальный уровень читающего, введя в обращение термин «интеллектуальный глянец». Позднее, начиная примерно с 2010 г., словосочетание «интеллектуальный глянец» начинает замещаться термином «качественная пресса/качественные СМИ». Можно предположить, что подобная смена терминологии маркирует стремление не ассоциировать далее формат с «глянцем», а перенести акцент на «качество» издания. «Качество», которое укрепляло бы у представителей воображаемых и/или реальных аудиторий ощущение собственного особого статуса.

Подобная репутация изданий позволяет нам предположить, что собственно медиа-формат содержит в себе одновременно элитистский дискурс и дискурс элитарности, формирующие представления о целевых аудиториях интересующих нас изданий как об элитарных группах, и, соответственно конструирующие, как минимум для части российских и русскоязычных читателей, определенные образцы элитарности и образы элит. В таком понимании, и сами медиа-проекты могут восприни- 


\section{Социальные страсти}

маться как статус-символы теми, кто хотел бы или готов считать себя представителем целевой аудитории таких изданий.

В данной статье, во многом продолжая нашу предыдущую работу, мы обратимся к вопросу о том, как именно, посредством каких дискурсивных стратегий, образ и репутация интересующих нас изданий в качестве изданий для «образованного меньшинства», “продвинутой” группы социума, конструируется в поле самих этих изданий. В порядке проверки полученных ранее результатов, мы уточним на более разнообразной выборке публикаций, насколько устойчиво представление об анализируемых проектах как об особенных, «качественных» медиа, противопоставленных «глянцу»; а о создателях и аудиториях подобных изданий как об «образованном меньшинстве», об узком круге «своих».

Для ответа на поставленный вопрос в статье анализируется корпус из 10 публикаций, охватывающих период с 2008 по 2013 гг., которые вышли в том или ином издании нашего списка и приурочены к запуску, изменению формата/смене концепции, закрытию или приостановке того или иного проекта из этого же списка. Сами по себе материалы такого рода, как мы уже писали ранее [3], очень показательны для анализа интересующего нас вопроса: именно в таких текстах проговариваются (зачастую, наиболее отчетливо) ключевые представления об исследуемых медиа-проектах как об адресованных представителям элитарных групп.

Основной принцип выбора публикаций для исследования, учитывая ограничения формата научной статьи, дополнительно уточнен: к анализу отобраны только те тексты, в которых высказывается непосредственно представитель издания (создатель, издатель, главный редактор, известный автор). Редакционные заметки-новости или аналитические статьи, посвященные различным событиям в изучаемых медиа, в представляемой работе не рассматриваются. Для удобства чтения приводимые далее в тексте подтверждающие цитаты снабжаются порядковым номером (римские цифры в круглых скобках) в соответствие с нумерацией внутри общего списка включенных в анализ Интернет-материалов. Список приведен в конце статьи.

Уточним также, что исследование ведется исключительно на материалах Интернет-публикаций. Подобный выбор обусловлен тем, что часть изданий списка с момента своего возникновения, в принципе, существуют только как online-медиа. Временно́е ограничение выборки (с 2008 по 2013 гг.) соответствует периоду, в течение которого произошло подавляющее большинство наиболее значимых для медиа-сегмента изменений.

Исследование проведено методом анализа дискурса. Метод представляется нам наиболее продуктивным аналитическим инструментом для работы с медийными репрезентациями, которыми являются публикации в наших источниках. Мы исходим из базового для традиции Cultural Studies положения о том, что репрезентации в СМИ, как один из возможных планов дискурсивной практики, обладают способностью одновременно отражать и конструировать представления о норме/нормативных образцах для тех или иных (со)обществ, а также, как правило, создавать иллюзию однородности той или иной общности, однозначности того или иного явления и т.п. [4] - скажем, образов элитарных групп и образцов демонстрации элитарности, как в случае интересующего нас вопроса.

Дискурс, в соответствии с фукодианской традицией, в рамках данной работы понимается как тип и практика высказывания (естественно-языкового, визуального, высказывания-действия), за которым стоит определенное обусловленное индивидуальным и социально-групповым опытом, мировосприятие (одновременно конституирующее и порождающее сам дискурс). При этом одним из ключевых свойств дискурса являются правила и условия допуска к дискурсу/в дискурс тех или иных потенциальных участников [5].

Наша работа актуальна в следующем исследовательском контексте. Если исходить из того, что представление о высоком социальном статусе напрямую связано с представлениями об элитах и элитарности, в случае современного российского общества мы имеем уточняющий аспект исследовательской проблемы. В соответствие с результатами исследования «Проблема элиты в сегодняшней России», проведенного авторитетными отечественными социологами из Левада-центра в середине 2000-х тысячных, в постсоветском обществе принципы и механизмы отбора в элиту устроены крайне непродуктивно: нормативным и решающим критерием в общем случае становится лояльность власти, а не наивысшие профессиональные достижения индивида. В перспективе подобная практика отбора в элиту, как считают социологи, губительна для развития и процветания всего общества [6]. 
Помимо такого рода сложностей в понимании оснований и механизмов обретения высокого социального статуса / попадания в элиту, характерных для современного российского общества, отдельное проблемное поле к настоящему моменту представляют процессы самоидентификации представителей тех социальных общностей, которые полагаются целевыми аудиториями интересующих нас изданий. Речь идет о людях/читателях/ пользователях, которые так или иначе готовы ассоциировать себя с групповыми названиями вроде «интеллигенция», «креативный класс», «образованный класс», «образованное сословие», «хипстеpы», Global Russians [7].

Нас в этом процессе, который уже достаточно интенсивно обсуждается и изучается современными (главным образом, отечественными) социологами, культурологами, политологами, филологами, философами [например: 8; 9; 10; 11], интересует, прежде всего, вопрос о системообразующей - для формирования и самоосознания этих групп - роли медиа-проектов из нашего списка. Нам представляется, что в интересующем нас случае речь идет о медиа-сегменте как институте, который формулирует, конструирует, представляет и поставляет своим читателям образцы, стратегии и способы (само)идентификации индивида в качестве представителя определенной элитарной группы/общности, которая полагается целевой аудиторией подобных изданий.

Притом исследований, посвященных тому, как именно эти издания формируют представления об элитарности своих читателей и соответственно о самих себе, как медийных проектах для "избранных" аудиторий, к настоящему моменту достаточно мало.

Так, в качестве наиболее полезных для освещения вопроса данной работы необходимо отметить публикации Эллен Руттен (Ellen Rutten) 'The Faces and Spaces of a Russian Culture-News Portal: www.openspace.ru' [12] и Тине Рёзен (Tine Roesen) 'www.snob.ru: A Social Network Site for the Elite' [13], которые представляют собой описание основных функциональных характеристик двух проектов из нашего списка: Snob.ru и Openspace.ru. Однако эти наблюдения относятся к 2010-2011 гг. В течение прошедших с этого момента трех-четырех лет изучаемые издания заметно менялись, пережив зачастую не одну смену концепции, а заодно руководства и, в некоторых случаях, значительной части редакционных коллективов. Подобная ситу- ация, в целом типичная для новых медиа, дополнительно интенсифицировалась протестами в ряде крупнейших российских городов в 2011-2012 гг. Издания медиа-сегмента воспринимали себя и воспринимались своими аудиториями как рупор этих самых аудиторий: настроенных оппозиционно действующей официальной власти, либерально и западно-ориентированных городских жителей, обеспеченных и наиболее образованных граждан современного российского общества. Поэтому закрытия и смена концепций в ряде изданий сегмента, произошедшие на пике протестной активности, многими участниками медиа рынка и читателями / пользователями связывались именно с политической позицией этих изданий.

Таким образом, размышления Э. Руттен и Т. Рёзен, являясь корректными, скорее всего, ограниченно репрезентативны, если говорить о периоде наблюдения в 3-5 лет. Учитывая изменения, которые произошли в поле исследуемого медиа-сегмента в последние несколько лет, наша выборка - тексты, в которых интересующие нас издания обсуждают сами себя - представляется более надежным источником для анализа репутаций исследуемых изданиях и образов их аудиторий как “элитарных". Подобные тексты, даже лишенные в ряде случаев (по техническим причинам) изначально сопровождавших их пользовательских комментариев, остаются в остальном неизменными и поэтому являются более информативными для изучения того, какие представления об основаниях попадания в элиту и способах обозначения сопряженного элитарного статуса конструируются в изучаемых изданиях. А поскольку целевыми аудиториями интересующие нас медиа-проекты полагают людей, которые с началом протестной активности в России в 2011-2012 гг. претендует (по крайней мере, в пространстве символической коммуникации) на организацию перемен в стране в целом, понимание того как устроены представления об элитах и элитарности у этой части отечественного социума важно для оценки сценариев развития всего российского общества в обозримом будущем.

Если теперь обратиться к источникам, то исходное предположение о противопоставлении себя отобранными проектами «глянцу» в смысле “типичному мейнстримному глянцу" в качестве стратегии конструирования особенности собственного формата и уникальности наполняющего его содержания действительно во многом подтверждается. Подобное противопоставление, как правило, 


\section{Социальные страсти}

сопровождается смыслом вне- или даже антисистемности этих медиа и одновременно их статуса эталонных (притом сам формат иногда полагается настолько нетиповым, что его даже сложно каклибо определить, назвать), системообразующих образцов, несущих новаторскую миссию по отношению не только к выбранному медиа-сегменту и, шире, к отечественному медиа-ландшафту, но и к обществу в целом. Например:

Первые годы русский Esquire был совершенно великим. Лучший журнал с большим отрывом, ничего рядом не стояло. (I)

Это говорит о том, что тот сложноформулируемый формат, о котором мы между собой договорились, работает. (III)

... многие вещи у «Сноба» я считаю просто выдающимися достижениями. (VIII)

Мы рисовали картину, в которой существование не сводится к ламентациям о том, как надоело жить в серой мерзости путинских нулевых и «неужели ничего невозможно поменять?». Поменять возможно, для начала хотя бы на бумаге. Сдвиньте чуть-чуть картинку - вам понравится, вас затяHem. (III)

Я не вполне готова сравнивать, потому что то, что мы делаем в «Снобе», на мой взгляд, не похоже на другие российские СМИ. Это и по формату экспериментальная история, и, соответственно, по принципам организации работы тоже. (VII)

На этом фоне можно предложить что-то совсем другое, что мы и пытаемся сделать. И это не шлягерная журналистика. (X)

В этом противопоставлении также присутствуют апелляция к понятиям и смыслам “искренность”, “честность”, “уважение к индивидуальности”, “экспериментальность”, “взрослость” в противопоставление «инфантильности», которые призваны характеризовать стиль работы и отношение к делу в изданиях списка в отличие от того, что происходит в “обычном глянце”, который представлен в качестве «машинки по зарабатыванию денег». Одновременно противопоставляется качество содержания и уровень тем “качественной прессы” и “глянцевого мейнстрима": заниматься «честными и искренними вещами» (без конкретизации) имплицитно представлено более значимым, нежели писать о «телках» и «материнских платах».

Если бы я работал главным редактором мужского журнала с телками или сайта, который сравнивает цены на материнские платы, наверное, все было бы по-другому. Но мы тут занимаемся честными и искренними вещами, и наши отношения отражаются на продуктах, которые мы делаем. Помоему, это хорошо, это работает. (IX)

Если ты играешь не в игру под названием журнал Glamour или Cosmopolitan, то есть в системные машинки по зарабатыванию денег, если помимо коммерческого успеха для тебя важно, чтобы твое дело было социальным явлением, меняло окружающий ландшафт, то бороться здесь с индивидуальностью бессмысленно. (VI)

На этом фоне можно предложить что-то совсем другое, что мы и пытаемся сделать. И это не шлягерная журналистика. За счет тех ходов, о которых я говорил, на рынке очень много инфантильного описания реальности. Стёба, приукрашивания. Одним словом, невзрослого отношения к миру. $A$ очень хочется сделать интересный взрослый журнал для взрослых людей. (X)

Но при этом сами издания списка, несмотря на декларируемое противостояние “глянцу/гламуру/мейнстриму”, часто, однако, обозначаются как «продукты», от которых ожидают окупаемости и прибыли. В анализируемых высказываниях в этой связи используется маркетологическая и финансовая лексика, скажем, слова «тренд», «рынок», «бренд»/«успешный бренд», «конкурентоспособность», «инвестиции», «акционер», «рекламодатели», равно как и риторика экономической эффективности и финансовой успешности проекта как показателя его востребованности и популярности у аудиторий. Более того, финансовая успешность проекта в этом случае зачастую представляется и одним из значимых подтверждений собственно качества содержания издания.

Надо сказать, я как человек, который занимается журналами не первый год, и сам вынашивал идею чего-то в этом роде под брендом GQ City, такого городского интеллектуального журнала, я чувствовал, что это сейчас будет востребовано 


\section{Психология и психотехника 1(76) • 2015}

обществом. И когда появился «Сноб», я обрадовался, что не только я чувствую этот тренд. (VIII)

А вообще, на самом деле расшаривание - это ерунда. Это не критерий успешности продукта. Критерием является тираж и стоимость рекламной полосы. ... Сейчас нужно идти за рынком, а реальность рынка такова, что ... (VIII)

Бренд «Афиша» делался - при всех загибах в одну или другую сторону - как история достаточно массовая с попыткой найти адекватный способ разговора со среднеинтеллигентным человеком, у которого есть культурные интересы, который живой и беспартийный в том смысле, что не является очевидным адептом какого-то одного тренда. (IX)

Это зависит не от читателя, а от рекламодателя ... (VII)

Показательно, что когда речь заходит о прибыльности проекта, риторика «экспериментальности», «сложносочиненности», “особости” медиаформата по сравнению "глянцевыми" «машинками по зарабатыванию денег» отчасти отодвигается на второй план, попутно обретая даже негативные коннотации. Так, «не вполне рыночный продукт» риторически может приравниваться к «не вполне конкурентноспособному», что, в пределе, ставит под сомнение ценность и значимость собственно проекта, в том числе, его контента. Одновременно на первый план в подобных высказываниях выходит представление о необходимости привлечения достаточно широкой аудитории, иногда даже с целью не столько рассказать что-то значимое как можно большему количеству людей, сколько быть интересными рекламодателю.

Не хочется обижать тех, кто делал «Сноб» раньше, но, по моему убеждению, они не использовали тот огромный карт-бланш, который получили от акционера. В том числе, финансовый. Впрочем, когда люди работают вне рынка, у них и продукт получается не вполне рыночный и конкурентоспособный. (VIII)

Мы считали и продолжаем придерживаться той точки зрения, что «Большой город» - очень хороший медиабренд и из него можно сделать успешное городское издание. ... Мне, как читателю, журнал нравился и в 2010-м, и в 2012-м году. Моя проблема, как инвестора, заключается в том, что нас, фанатов «БГ», пока не слишком много (115 тысяч человек в Москве, по данным TNS) и журнал пока недостаточно высоко оценен рекламодателями. Эту ситуацию нужно обязательно изменuть. (IV)

Отметим, в продолжение, два характерных аспекта противоречия между риторикой уникальности формата и рассуждениями о необходимости привлекать «достаточно массового» читателя и быть прибыльным проектом.

Во-первых, это видение читателя как потребителя, предъявляющего, с одной стороны, запрос на содержание, маркируемое как «интеллектуальное», а с другой стороны - достаточно массового, для того чтобы представлять интерес в качестве целевой аудитории медиа-проекта как коммерческого «медийного упражнения». В этой связи предпринимается попытка дифференциации «среднеинтеллигентного человека», «живого и беспартийного» как адресата издания от неких «интеллектуалов», которые могут быть интересны в качестве близких друзей, но которых слишком мало, и поэтому они не интересны в качестве аудитории претендующего на статус системообразующего, но одновременно и коммерчески успешного, СМИ.

Образ аудитории как “меньшинства” представляется в данном случае несколько менее однозначным по сравнению с тем, что был выявлен нами в ходе анализа серии публикаций «Разговоры о медиа» в издании «Афиша» [14].

С одной стороны, например, в рассуждениях о проекте Snob.ru, аудитория представлена как «ограниченный круг людей», притом, характерно, с уточнением о том, что именно такие читатели «интересны нашим рекламодателям». При этом в рассуждениях о подобных читательских аудиториях как о "меньшинстве" наблюдается отстройка от концепции «нас читают три олигарха во всем мире», которая заменяется идеей «закрытого клуба», предполагающая большее, хотя также ограниченное число участников:

И все-таки о существовании «Сноба» не знают 98 процентов россиян.

Думаете, «Афишу» и GQ читают все?... Толстые умные журналы всегда будут востребованы ограниченным кругом людей - думающих, образованных, успешных, любопытных. Для них мы и работаем, это и есть новая Россия. Это, в конце концов, люди, которые интересны нашим рекламодателям. (VIII) 


\section{Социальные страсти}

Вот этот вот имидж «нас читают три олигарха во всем мире» вы будете каким-то образом менять?

- Такого, вроде, уже нет. Есть закрытый клуб, в котором люди покупают членство, и это хорошо. Я не считаю, что клуб, существующий на сайте и в офлайне, это то же самое, что журнал. Это два разных, хоть и близких друг к другу, продукта - ну, как журнал GQ и GQ Bar. (VIII)

Наряду с этим (и с поправкой на историю создания или существования того или иного конкретного издания из анализируемого списка - в частности, издания «Афиша»), предлагается концепция некой “немассовой” аудитории, состоящей из «среднеителлигентных людей». Притом как раз полагаемый достаточно высоким уровень образованности таких людей и соответствующий запрос с их стороны на «качественный» контент позволяют рассматриваемым медиа-проектам претендовать на статус изданий, которые представляют собой лучшие, эталонные образцы продукта такого типа. Одновременно численность подобного рода “немассовой” аудитории все же полагается достаточно значительной для того, чтобы проекты оказались заметны на медийном рынке в целом и могли заявлять о собственной востребованности, влиятельности, популярности и т.п, в том числе в категориях финансовой успешности.

Бренд «Афиша» делался - при всех загибах в одну или другую сторону - как история достаточно массовая с попыткой найти адекватный способ разговора со среднеинтеллигентным человеком, у которого есть культурные интересы, который живой и беспартийный в том смысле, что не является очевидным адептом какого-то одного тренда. Интеллектуалы меня никогда не интересовали как целевая аудитория, ... их слишком мало, чтобы разговор с ними оказался реально медийным упражнением, а меня все-таки интересуют медиа. (IX)

Во-вторых, несмотря на отмеченное выше противопоставление изданий нашего списка "мейнстриму" и “обычному глянцу", поднимается вопрос о том, а возможно ли - и если да, по каким основаниям и в какой степени это допустимо делать без ущерба для репутации проекта - считать сами анализируемые медиа «глянцевыми». Здесь наблюдается несколько стратегий.

В общем случае - принадлежность к «глянцу» отрицается или, в более мягком варианте, ассоци- ация с подобным медиа-форматом представляясь нежелательной. Вводится даже определение формата изданий списка как не то что “неглянцевого", а «антиглянцевого», т.е. подчеркивающего смысл не просто отличия форматов, а, скорее, их противостояния. В качестве надежных подтверждений «антиглянцевости» в этом случае заявляются: «неглянцевая бумага» (если речь идет о бумажных воплощениях проектов), «отсутствие селебрити» (притом что на ресурсах высказываются известные и публичные персоны из разных сфер деятельности), наличие «длинных текстов» и невозможность их «не читать» (о чем эти тексты, однако, уточняется лишь в единичных случаях, об этом см. ниже). Например:

«Сноб» - это не глянец. У «Сноба» нет никаких родовых признаков глянца. Во-первых, глянцевая бумага, которой у нас нет; во-вторых, селебрити, которых у нас нет; в-третьих, формат, который позволяет не читать статьи - его тоже нет. ... Наш журнал сделан так, что если ты не собираешься читать длинные тексты, он тебе ни к чему. Это подход совершенно антиглянцевый. (VII)

Идея «длинного текста» как характерного именно для изданий сегмента маркера «антиглянцевости» уточняется мыслью о том, что этот текст читается «потому что хочется, а не потому, что надо». В подобных высказываниях можно предполагать в качестве имплицитного смысла одной из ключевых задач собственного «длинного текста» - дать читателю отдохнуть «от мира, который постоянно меняется», что в пределе приводит к парадоксу, потому функционально стратегия отвлечения читателя от повседневных забот и проблем типична как раз для “обычного глянца”.

... у людей сейчас абсолютно иные запросы. Когда мир все время меняется, у вас абсолютно конкретная потребность: вам надо читать газеты. Или сайт. Или журнал. Вы делаете это, потому что вам это необходимо. Сегодняшнее общество потребности в этом практически не испытывает. Поэтому принции «Сноба» заключается в том, что читают не потому, что надо, а потому, что хочется. $(X)$

Предельным вариантом «длинного текста», своего рода конкурентным преимуществом по этому параметру и, видимо, неоспоримым доказательством особого качества и статуса издания 


\section{Психология и психотехника 1(76) • 2015}

становятся «литературные номера» (можно предполагать как целые собрания «длинных текстов»):

Вторым важным достижением я считаю то, на что не решился ни один из крупных журналов ни GQ, ни Esquire, ни «Афиша», - это литературные номера. А у «Сноба» они есть, и я могу сказать - выдающиеся. (VIII)

В качестве наиболее убедительного примера «хорошего / идеального текста»в одном из высказываний названы лекции известного российского ученого, специалиста по институциональной экономической теории Александра Аузана. При предполагающейся сложности и одновременно качественности (эти смыслы подкрепляются как статусом и известностью лектора, так и упоминанием нобелевских премий, получаемых за такого типа знание) лекций экономиста, они преподносятся как «развлечение» и приравниваются к «стендапвыступлениям».

Идеальный эсквайровский текст это, например, лекции Александра Аузана - они описывают не самую простую институциональную теорию, за развитие которой люди год за годом получают нобелевские премии, и при этом каждая его лекция - это чистое развлечение, набор остроумных примеров и метафор, парадоксальных выводов - все, на чем строится стендап-выступление. (II)

Наконец, завершая аналитический блок о противопоставлениях формата в логике "глянецнеглянец-антиглянец" или “обычный глянец vs нескучный журнал для умных" в рамках анализируемого дискурса, отметим следующее.

Во-первых, одновременно с отстройкой от “типичного отечественного глянца" создатели проектов рассматриваемой медиа-ниши образцами для себя, прямо или косвенно, заявляют наиболее известные зарубежные издания (разной степени “глянцевости"), имеющие репутацию наиболее влиятельных, в т.ч. в глобальном масштабе, медиа для образованных аудиторий. В список подобных образцов попадают The New Yorker, Vanity Fair, New York Times Magazine и некоторые другие. Например:

Я очень люблю воскресный New York Times Magazine. Когда-то были прекрасные журналы Wired (в его прошлой инкарнации) и Lingua Franca, который закрылся. Я в обязательном порядке читаю Vanity Fair, New Yorker... Это такие столпы, что даже смешно говорить, что они мне нравятся. (VII)

Информацию о ... вещах, интересующих меня, приходится выуживать из разных, далеко не только русскоязычных источников. Из ... отдела культуры The Guardian или, скажем, журнала The New Yorker - который не вполне журнал о культуре, но для меня расставляемые им акценты тоже почему-то важны. (V)

Во-вторых, в упоминаниях конкурентов по медиа-нише можно заметить попытку выстраивания иерархии значимости и качества того или иного издания внутри рассматриваемого медийного сегмента (или в пересечение этого сегмента с близкими, но все же закрепившими за собой в большей степени статус “обычного глянца" проектами вроде GQ). В этом случае критериями значимости издания по гамбургскому счету, а также собственно его принадлежности к рассматриваемому нами сегменту, полагаются: «расшаривание в фейсбуке» (т.е. “настоящий” интерес аудитории) и, опять же, «хорошие тексты». А такие “рыночные” достижения как успех у рекламодателей представлены если не вторичными, то, по крайней мере, не теми, к которым можно «испытывать зависть»:

Со «Снобом» вам сейчас явно придется потрудиться. К примеру, в том же фейсбуке материалы из «Сноба» расшариваются раз в 20 реже, чем у телеканала "Дождь», или сайта OpenSpace.ru, или журнала Esquire. (VIII)

GQ является конкурентом Esquire в борьбе за рекламные бюджеты. В остальном, на мой вкус, у этих журналов совершенно разные амбиции и то, чем занимаются ребята в $G Q$, меня совершенно не интересует. Я скорее могу испытывать зависть к хорошему тексту в «Афише» или на OPENSPACE. RU. (II)

В заключение представим основные выводы по итогам проведенного исследования.

Во-первых, в ходе анализа подтверждено исходное предположение о противопоставлении себя отобранными проектами тому, что видится ими как издания для массовой аудитории - «глян- 


\section{Социальные страсти}

цу». Подобное противопоставление, возникающее в ходе конструирования особенности собственного формата и уникальности наполняющего его содержания, как правило, сопровождается смыслом вне- или даже антисистемности «качественных» медиа и одновременно их статуса эталонных, несущих новаторскую миссию по отношению не только к выбранному медиа-сегменту и, шире, к отечественному медиа-ландшафту, но и к обществу в целом.

Притом и это во-вторых, риторика особенного статуса того или иного медиа исследуемого сегмента нивелируется, когда речь заходит об экономических аспектах существования подобных проектов. В этих случаях происходит обращение к лексикону и логике финансового и маркетологических дискурсов, когда значимость издания имеет тенденцию формулироваться в терминах привлекательности медиа-проекта, в первую очередь, для рекламодателей.

В-третьих, видимо, как раз в силу влияния финансово-маркетологической риторики образ целевой аудитории, в предыдущем исследовании представленный как образ «просвещенного меньшинства» и выявленный и в данном исследовании тоже, все же дополняется здесь образом «среднеинтеллигентного человека». Подобный читатель представлен достаточно образованным для того, чтобы интересоваться содержанием издания и одновременно достаточно массовым для того, чтобы заинтересовать рекламодателя и сделать проект прибыльным.

B-четвертых, в качестве базовой характеристики, определяющей "неглянцевость" или даже «антиглянцевость» того или иного издания изучаемого списка полагается «длинный текст», имплицитно представляемый в логике анализируемого дискурса как «качественный текст». Притом функция подобного текста полагается все же, во многом, «развлекательной».

Наконец, наблюдаются попытки выстраивать иерархию изданий в пределах самого сегмента. В этом случае, более значимое место полагается за теми проектами, которые наиболее популярны у читателей-пользователей социальной сети Facebook. Это наблюдения также соотносится с результатами нашей предыдущей статьи, в которой пользователи Facebook (в отличие от пользователей проектов «ВКонтакте» или «Одноклассники») полагались принадлежащими к «своим»/«меньшинству» [15]. Таким образом, значимость проекта по гамбургскому счёту определяется, видимо, в первую очередь, оценкой и одобрением «своего круга».

\section{Список литературы:}

1. Ельцова К.К. «Качественные медиа» для «образованного меньшинства»: анализ дискурса об элитарности в российских новых медиа // Философия и культура. 2014. № 8. С. 1149-1175.

2. Ельцова К.К. Дискурсы об элитарных группах в современной России (анализ публикаций в новых медиа) // Вестник РГГУ. Серия Политология. 2015. (в печати).

3. Hall S. The Work of Representation // Representation: Cultural Representation and Signifying Practices, The Open University 1997, pp. 13-75.

4. Фуко М. Порядок дискурса // Воля к истине: по ту сторону знания, власти и сексуальности. Работы разных лет / Пер. с франц. М.: Касталь, 1996. 448 с.

5. Гудков Л., Дубин Б., Левада Ю. Проблема элиты в сегодняшней России. М., 2007.

6. Куренной В.А. Новая городская романтика. Политические и культур-социальные аспекты новейшего российского протеста // Логос. 2012. № 2. С. 30-45.

7. Калинин И.В. Индустриальный горизонт креативных индустрий // Неприкосновенный запас. 2013. № 6(92). (http:// magazines.russ.ru/nz/2013/6/14k.html).

8. Трубина Е.Г. Примиряясь с упадком. Руины 2.0 // Неприкосновенный запас. 2013. № 3(89). (http://magazines.russ.ru/ nz/2013/3/14t-pr.html).

9. Программа и материалы конференции 'Middle' and 'Creative': Emerging Russian Social Groups in Language and in Culture, состоявшейся 26-25 октября 2013 г. в Центре принцессы Дашковой Эдинбургского университета. (http:// www.ed.ac.uk/schools-departments/literatures-languages-cultures/dashkova/research-resources/middle-creativeprogramme/).

10. Rutten E. The Faces and Spaces of a Russian Culture-News Portal: www.openspace.ru, Digital Icons: Studies in Russian, Eurasian and Central European New Media, №6 (2011): 93-103.

11. Roesen T. www.snob.ru: A Social Network Site for the Elite, Digital Icons: Studies in Russian, Eurasian and Central European New Media, №6 (2011): 81-92.

12. Ельцова К.К. «Качественные медиа» для «образованного меньшинства»: анализ дискурса об элитарности в российских новых медиа // Философия и культура. 2014. № 8. С. 1149-1175. 


\section{Психология и психотехника 1(76) • 2015}

Список электронных ресурсов, не входящих в основной корпус анализируемых публикаций:

13. Интернет-публикация «Максим Ковальский опубликовал статью Михаила Ходорковского в журнале “КоммерсантъВласть"», (16.06.2009; http://www.snob.ru/fp/entry/3900?preview=print).

14. Интернет-публикация «Дмитрий Голубовский: “Esquire как нарушал, так и будет нарушать” (16.11.2011; http:// os.colta.ru/media/paper/details/31881/?expand=yes\&attempt=1).

15. Интернет-публикация «Прямая речь: главный редактор Esquire Филипп Бахтин», (апрель 2010 г; http://besttoday. $\mathrm{ru} / \mathrm{read} / 515 . \mathrm{html})$.

16. Интернет-публикация «Это звенья одной гребаной цепи» на портале Openspace (2008-2012), (07.06.2012; http:// os.colta.ru/media/paper/details/37626).

\section{Список анализируемых источников:}

I. Бахтин: дрянь пойдет своей дорогой. (http://gorod.afisha.ru/archive/bahtos; дата обращения 28.07.2014).

II. Бахтин: меня перестала радовать суть профессии. (http://os.colta.ru/media/paper/details/30364/; дата обращения 28.07.2014).

III. Большой Город - не открытое письмо чиновникам. (http://os.colta.ru/media/paper/details/14976/; дата обращения 28.07.2014).

IV. Винокуров: Интернет и журнал в кафе - непопулярные каналы дистрибуции контента у служб режима. (http:// os.colta.ru/media/paper/details/37673/; дата обращения 28.07.2014).

V. Город, воздух и волна. (http://www.colta.ru/articles/media/859; дата обращения 28.07.2014).

VI. Казаков: для Ильи это было системным сбоем. (http://os.colta.ru//media/paper/details/1914/; дата обращения 28.07.2014).

VII. Прямая речь: Маша Гессен. (http://www.lookatme.ru/flow/posts/media-radar/115607-pryamaya-rech-masha-gessen; дата обращения 28.07.2014).

VIII. Усков: не хочется обижать тех, кто делал Сноб раньше. (http://gorod.afisha.ru/archive/uskov-snob/; дата обращения 28.07.2014).

IX. Ценципер: По образованию я директор цирка. (http://os.colta.ru/media/paper/details/12050/?expand=yes\# expand; дата обращения 28.07.2014).

Х. Яковлев: Сноб - это не шлягерная журналистика. (http://os.colta.ru/media/paper/details/3763/; дата обращения 28.07.2014).

\section{References (transliteration):}

1. El'tsova K.K. «Kachestvennye media» dlya «obrazovannogo men'shinstva»: analiz diskursa ob elitarnosti v rossiiskikh novykh media // Filosofiya i kul'tura. 2014. № 8. S. 1149-1175.

2. El'tsova K.K. Diskursy ob elitarnykh gruppakh v sovremennoi Rossii (analiz publikatsii v novykh media) // Vestnik RGGU. Seriya Politologiya. 2015. (v pechati).

3. Hall S. The Work of Representation // Representation: Cultural Representation and Signifying Practices, The Open University 1997, pp. 13-75.

4. Fuko M. Poryadok diskursa // Volya k istine: po tu storonu znaniya, vlasti i seksual'nosti. Raboty raznykh let / Per. s frants. M.: Kastal', 1996. $448 \mathrm{s.}$

5. Gudkov L., Dubin B., Levada Yu. Problema elity v segodnyashnei Rossii. M., 2007.

6. Kurennoi V.A. Novaya gorodskaya romantika. Politicheskie i kul'tur-sotsial'nye aspekty noveishego rossiiskogo protesta // Logos. 2012. № 2. S. 30-45.

7. Kalinin I.V. Industrial'nyi gorizont kreativnykh industrii // Neprikosnovennyi zapas. 2013. № 6(92). (http://magazines.russ. $\mathrm{ru} / \mathrm{nz} / 2013 / 6 / 14 \mathrm{k} \cdot \mathrm{html})$.

8. Trubina E.G. Primiryayas' s upadkom. Ruiny 2.0 // Neprikosnovennyi zapas. 2013. № 3(89). (http://magazines.russ.ru/ nz/2013/3/14t-pr.html).

9. Programma i materialy konferentsii 'Middle' and 'Creative': Emerging Russian Social Groups in Language and in Culture, sostoyavsheisya 26-25 oktyabrya 2013 g. v Tsentre printsessy Dashkovoi Edinburgskogo universiteta. (http://www.ed.ac. uk/schools-departments/literatures-languages-cultures/dashkova/research-resources/middle-creative-programme/).

10. Rutten E. The Faces and Spaces of a Russian Culture-News Portal: www.openspace.ru, Digital Icons: Studies in Russian, Eurasian and Central European New Media, № 6 (2011): 93-103.

11. Roesen T. www.snob.ru: A Social Network Site for the Elite, Digital Icons: Studies in Russian, Eurasian and Central European New Media, № 6 (2011): 81-92.

12. El'tsova K.K. «Kachestvennye media» dlya «obrazovannogo men'shinstva»: analiz diskursa ob elitarnosti v rossiiskikh novykh media // Filosofiya i kul'tura. 2014. № 8. S. 1149-1175. 


\section{Spisok elektronnykh resursov, ne vkhodyashchikh v osnovnoi korpus analiziruemykh publikatsii:}

13. Internet-publikatsiya «Maksim Koval'skii opublikoval stat'yu Mikhaila Khodorkovskogo v zhurnale "Kommersant"-Vlast'”», (16.06.2009; http://www.snob.ru/fp/entry/3900?preview=print).

14. Internet-publikatsiya «Dmitrii Golubovskii: “Esquire kak narushal, tak i budet narushat'” (16.11.2011; http://os.colta.ru/ media/paper/details/31881/?expand=yes\&attempt=1).

15. Internet-publikatsiya «Pryamaya rech': glavnyi redaktor Esquire Filipp Bakhtin», (aprel' 2010 g; http://besttoday.ru/ $\mathrm{read} / 515 . \mathrm{html})$.

16. Internet-publikatsiya «Eto zven'ya odnoi grebanoi tsepi» na portale Openspace (2008-2012), (07.06.2012; http://os.colta. $\mathrm{ru} /$ media/paper/details/37626).

\section{Spisok analiziruemykh istochnikov:}

I. Bakhtin: dryan' poidet svoei dorogoi. (http://gorod.afisha.ru/archive/bahtos; data obrashcheniya 28.07.2014).

II. Bakhtin: menya perestala radovat' sut' professii. (http://os.colta.ru/media/paper/details/30364/; data obrashcheniya 28.07.2014).

III. Bol'shoi Gorod - ne otkrytoe pis'mo chinovnikam. (http://os.colta.ru/media/paper/details/14976/; data obrashcheniya 28.07.2014).

IV. Vinokurov: Internet i zhurnal v kafe - nepopulyarnye kanaly distributsii kontenta u sluzhb rezhima. (http://os.colta.ru/ media/paper/details/37673/; data obrashcheniya 28.07.2014).

V. Gorod, vozdukh i volna. (http://www.colta.ru/articles/media/859; data obrashcheniya 28.07.2014).

VI. Kazakov: dlya Il'i eto bylo sistemnym sboem. (http://os.colta.ru//media/paper/details/1914/; data obrashcheniya 28.07.2014).

VII. Pryamaya rech': Masha Gessen. (http://www.lookatme.ru/flow/posts/media-radar/115607-pryamaya-rech-masha-gessen; data obrashcheniya 28.07.2014).

VIII. Uskov: ne khochetsya obizhat' tekh, kto delal Snob ran'she. (http://gorod.afisha.ru/archive/uskov-snob/; data obrashcheniya 28.07.2014).

IX. Tsentsiper: Po obrazovaniyu ya direktor tsirka. (http://os.colta.ru/media/paper/details/12050/?expand=yes\# expand; data obrashcheniya 28.07.2014).

X. Yakovlev: Snob - eto ne shlyagernaya zhurnalistika. (http://os.colta.ru/media/paper/details/3763/; data obrashcheniya 28.07.2014). 